\title{
Introducing Hypothesis: Failure
}

Heather N. Holmes, MLIS, AHIP

Associate Director of Libraries, Associate Professor

Medical University of South Carolina

Charleston, SC

Welcome to the inaugural Hypothesis: Failure column. It is our sincere hope that readers will benefit from the lessons learned by their colleagues, and will contribute their own stories to help others.

Our first article comes to us from Elaine Wells, Library Director of the SUNY College of Optometry, about a renovation project. This article is especially exciting to me because my current library is preparing for a renovation to begin next year. Renovation is one of the words that librarians love to hear and then immediately cringe at what it might actually mean. In my past experience, when a library undergoes a renovation it is because someone else needs space. This isn't always a bad thing, and in fact I think in some cases it has worked out to the benefit of the library; however, I think it is fair to say that in a good number of cases the library (and more importantly, our patrons) gets the short end of the stick. That is not always the case though, as you'll see in the contributed article.

As far as the renovation at my library, I think we'll be seeing both great benefits, and having some pains due to losing a lot of space. The loss of space, however, isn't really being taken from the students but rather being redistributed throughout the building which houses other spaces besides the library. There will be some muchneeded improvements to our built-in-1968-building, the most anticipated being access to electricity from places other than the perimeter of the building. Furniture upgrades, and soundproofing of walls are also things we're really looking forward to. The effects of the loss of space remain to be seen, but one positive is that all of the faculty and staff (except for 2 people) will be on the same floor. We hope this leads to improved workflows but there is a fair bit of concern about staff who currently have substantial workspaces being moved into cubicles. Perhaps I can contribute my own article to this column in a couple years when ours is completed!

Sharing information is at the base of what we as librarians do so we owe it to each other to let others learn from our experiences. We hope you'll consider submitting your own articles for future issues.

Heather N. Holmes 